\title{
Immigration and establishment of urban Trypanosoma cruzi populations
}

4 Alexander S.F. Berry ${ }^{1,2}$, Renzo Salazar-Sánchez ${ }^{3}$, Ricardo Castillo-Neyra ${ }^{3,4}$, Katty Borrini-

5 Mayorí $^{3}$, Claudia Chipana-Ramos ${ }^{3}$, Melina Vargas-Maquera ${ }^{3}$, Jenny Ancca-Juarez ${ }^{3}$, César

6 Náquira-Velarde ${ }^{3}$, Michael Z. Levy ${ }^{3,4}$, Dustin Brisson ${ }^{2}$ and the Chagas Disease Working Group

7 in Arequipa

9 'Division of Gastroenterology, Hepatology, and Nutrition, Children's Hospital of Philadelphia,

10 Philadelphia, PA, USA

11 2Department of Biology, University of Pennsylvania, Philadelphia, PA, USA

12 Universidad Peruana Cayetano Heredia/University of Pennsylvania Zoonotic Disease Research

13 Laboratory, Arequipa, Peru

$14{ }^{4}$ Department of Biostatistics, Epidemiology and Informatics, The Perelman School of Medicine

15 of the University of Pennsylvania, Philadelphia, PA, USA

16

18 To whom correspondence should be addressed: Dustin Brisson, Department of Biology,

19 University of Pennsylvania, 433 S. University Ave., Philadelphia, PA 19104, USA; email:

20 dbrisson@sas.upenn.edu

22 Running Title: Immigration and establishment of natural Trypanosoma cruzi populations 


\section{Abstract}

24 Changing environmental conditions, including those caused by human activities, reshape

25 biological communities through both loss of native species and establishment of non-native

26 species in the altered habitats. Dynamic interactions with the abiotic environment impact both

27 immigration and initial establishment of non-native species into these altered habitats. The

28 repeated emergence of disease systems in urban areas worldwide highlights the importance of

29 understanding how dynamic migratory processes affect the current and future distribution and

30 abundance of pathogens in urban environments. In this study, we examine the pattern of invasion

31 of Trypanosoma cruzi - the causative agent of human Chagas disease - in the city of Arequipa,

32 Peru. Phylogenetic analyses of 136 T. cruzi isolates from Arequipa and other South American

33 locations suggest that only one $T$. cruzi immigrant established a population in Arequipa as all $T$.

34 cruzi isolated from vectors in Arequipa form a recent monophyletic group within the broader

35 South American phylogeny. We discuss several hypotheses that may explain the limited number

36 of established T. cruzi lineages despite multiple introductions of the parasite. 


\section{Author Summary}

38 Human-associated pests and pathogens, who benefit from the abundance of humans and human-

39 associated hosts or vectors, commonly invade environments altered by human activities. As the

40 number and size of human-disturbed environments increase, so does the importance of

41 identifying ecological and environmental factors that affect the probability that disease systems

42 immigrate to, subsequently establish populations in, urban environments. We examined the

43 number and timing of immigration and establishment events of Trypanosoma cruzi, the causative

44 agent of Chagas disease, in a currently endemic area. Phylogenetic analyses of 136 T. cruzi

45 isolates suggests that the current population descended from a single, recent immigration event.

46 We discuss historical and ecological hypotheses that can explain the limited T. cruzi diversity in

47 this region. 


\section{Introduction}

Habitat alterations are transforming biological communities worldwide [1-3]. The current and future geographic distributions of many species in disturbed environments depends upon their interactions with novel biotic and abiotic features during immigration and while establishing a growing population [4]. Although many species fail to establish thriving

53 populations in altered habitats, others are well-suited to migrate to, and prosper in, these novel

54 environments. For example, several populations of plant [5-7], insect [8-11], mammal [12,13],

55 and bird $[14,15]$ species are severely diminished or suffer local extinctions in recently urbanized

56 environments [1], while several microbial species benefit from the abundance of humans and

57 human-associated hosts or vectors in similar habitats [16]. Although conservation efforts have

58 focused primarily on the impacts of environmental changes on native plant and animal species,

59 establishment or population growth of disease-causing microbial populations can have a strong

60 negative impact on populations of native flora and fauna [17] in addition to their impact on

61 human health and economy [18]. The rate or impacts of invasions of infectious microbes may be

62 mitigated through public health programs based on an understanding of the dynamic processes

63 determining immigration and establishment rates. The regularity at which disease systems are

64 emerging in many urban and urbanizing areas underscores the importance of understanding how

65 disease-causing microbes migrate to, and establish in, urban environments [16], one of the most

66 dramatic examples of habitat alteration [19,20]. In this study, we examine the patterns of

67 invasion of Trypanosoma cruzi - the causative agent of Chagas disease in humans - into the city

68 of Arequipa, Peru.

69 Invasion of a new environment by a pathogen occurs in three stages: (1) immigration, or the

70 movement of an individual to the new environment; (2) establishment of a population via 
71 reproduction and population growth; and (3) local dispersal [4]. The many studies focusing on

72 outbreaks of disease systems have generated a wealth of knowledge concerning factors affecting

73 population growth [21,22] and considerable progress in understanding local dispersal [23]. For

74 example, prior studies concluded that human-created containers increase the abundance of

75 standing water that provide breeding habitats for the mosquitos that spread dengue virus [24].

76 Relatively few studies, by contrast, have investigated the early stages of invasion, the

77 immigration and establishment processes, due to the practical difficulties of collecting the

78 necessary data before a novel species is established.

79 The Chagas disease system in Arequipa, Peru, provides an ideal system in which to study the

80 early invasion processes in urban environments. Arequipa has experienced rapid urbanization

81 and human population growth in the previous half century with a concurrent population of $T$.

$82 \quad c r u z i[25]$. The expansion in population sizes and geographic range of humans and their domestic

83 animals provide hosts for both T. cruzi and its primary insect vector, Triatoma infestans [26-31].

84 The population history of the T. cruzi currently in Arequipa - including the geographic locations

85 of the migrants that established the current population, the rate at which migrants enter and

86 establish in the area, and the age of each established lineage - have not been investigated. Here,

87 we performed phylogenetic analyses of maxicircle DNA, a non-recombining circular element

88 analogous to mitochondrial DNA, to estimate the number of independent T. cruzi lineages

89 established in Arequipa and to estimate the timing of each establishment event. We assessed

90 whether extant T. cruzi in Arequipa form a single monophyletic clade, indicative of the

91 establishment of a single migrant lineage, or multiple diverse clades, indicative of multiple

92 independent immigration and establishment events. 


\section{Results}

95 The maxicircle sequence is useful for population genetic and phylogenetic analyses because

96 it is conserved among diverse $T$. cruzi lineages and is likely non-recombining [32]. While there

97 was substantial maxicircle sequence diversity among samples across South America, almost no

98 diversity was observed among the samples from Arequipa. Over 13\% (2055/15367bp) of the

99 maxicircle sites were polymorphic among all 136 samples while only 16 sites were polymorphic

$100(0.1 \%)$ among the 123 samples collected within Arequipa (Table 1). Similarly, estimates of

101 diversity among the samples from Arequipa derived from population genetic statistics were

102 substantially lower than the total diversity across all samples $\left(\pi=6.8^{*} 10^{-5}\right.$ vs $8.18^{*} 10^{-3}$;

$103 \theta=1.93 * 10^{-4}$ vs $2.44 * 10^{-2}$; average pairwise distance 1.04 vs 126$)$. In contrast to the limited

104 genetic diversity within Arequipa, other locales from which multiple isolates were sampled

105 contain substantial genetic diversity among limited samples $(\mathrm{N}<3$; Fig 1).

106 Table 1. Population Genetic Statistics.

\begin{tabular}{|c|c|c|c|c|}
\hline & $\begin{array}{c}\text { Average } \\
\text { Pairwise } \\
\text { Distance }\end{array}$ & $\pi$ & $\theta$ & $\begin{array}{c}\text { Segregating } \\
\text { Sites }\end{array}$ \\
\hline All samples $(\mathrm{N}=136)$ & 126 & $8.18^{*} 10^{-3}$ & $2.44^{*} 10^{-2}$ & 2055 \\
\hline Arequipa (N=123) & 1.04 & $6.80^{*} 10^{-5}$ & $1.93 * 10^{-4}$ & 16 \\
\hline $\begin{array}{c}\text { South America } \\
(\mathrm{N}=13)\end{array}$ & 728 & $4.73 * 10^{-2}$ & $4.24 * 10^{-2}$ & 2022 \\
\hline La Esperanza $(\mathrm{N}=3)$ & 643 & $4.18^{*} 10^{-2}$ & $4.18^{*} 10^{-2}$ & 964 \\
\hline
\end{tabular}

107

The monophyletic group containing all 123 samples derived from T. infestans and domestic

109 animals collected in Arequipa coalesce in the very recent past, despite collection sites extending

110 throughout Arequipa and surrounding towns across 7 years (Fig 1). One sample derived from an

111 infected human in Arequipa (Fig 1C) belongs to a lineage that is more closely related to samples 
112 collected in Rio Grande, Brazil than to the other samples collected in Arequipa (Fig 1). This

113 sample is distinct from all other samples in Arequipa suggesting that T. cruzi can immigrate to

114 Arequipa but may not establish in the vector population. The population size of an unsampled $T$.

115 cruzi lineage - if present in the T. infestans population - must be at least 42 times smaller than

116 the dominant population in Arequipa to have remained undetected by chance $(\mathrm{p}<0.05)$.

117 In contrast to the monophyletic ancestry found in Arequipa, genetic diversity was apparent in

118 the samples collected from other regions, despite limited numbers of samples $(\mathrm{N}<3)$. Population

119 genetic diversity among the three samples collected La Esperanza, a town of 57 houses in the

120 Cutervo Province of Cajamarca, Peru $\left(\pi=4.18^{*} 10^{-2} ; \theta=4.18^{*} 10^{-2}\right)$, are much larger than those in

121 Arequipa despite the limited number of samples [33]. There is no statistical correlation between

122 genetic relatedness and geographic distance among South American samples (Table 2). For

123 example, while proximal towns La Esperanza and Campo Florido, Peru have closely related $T$.

$124 c r u z i$, isolates from cities around Brazil encompass nearly the total genetic diversity. 


\section{Table 2. Distance matrix showing average pairwise SNP distance between samples (bottom}

135 triangle) and Euclidean distance between sample collection locations (top triangle).

\begin{tabular}{|c|c|c|c|c|c|c|c|c|c|c|c|}
\hline & $\begin{array}{c}\text { (A) } \\
\text { Arequipa, } \\
\text { Peru }\end{array}$ & $\begin{array}{c}\text { La } \\
\text { Esperanza, } \\
\text { Peru }\end{array}$ & $\begin{array}{c}\mathrm{La} \\
\text { Esperanza, } \\
\text { Peru }\end{array}$ & \begin{tabular}{|c|} 
(B) La \\
Esperanza, \\
Campo Florido, \\
\& Naranjal, Peru \\
\end{tabular} & Bolivia & Bolivia & $\begin{array}{l}\text { (C) Arequipa, } \\
\text { Peru - Human }\end{array}$ & $\begin{array}{c}\text { São Paulo, } \\
\text { Brazil }\end{array}$ & $\begin{array}{c}\text { Para State, } \\
\text { Brazil }\end{array}$ & $\begin{array}{c}\text { Bahia State, } \\
\text { Brazil }\end{array}$ & $\begin{array}{c}\text { Rio Grande, } \\
\text { Brazil }\end{array}$ \\
\hline $\begin{array}{c}\text { (A) } \\
\text { Arequipa, } \\
\text { Peru }\end{array}$ & & $1400 \mathrm{~km}$ & $1400 \mathrm{~km}$ & $1400 \mathrm{~km}$ & $700 \mathrm{~km}$ & $700 \mathrm{~km}$ & $0 \mathrm{~km}$ & $2700 \mathrm{~km}$ & $2500 \mathrm{~km}$ & $3200 \mathrm{~km}$ & $2500 \mathrm{~km}$ \\
\hline $\begin{array}{c}\text { La } \\
\text { Esperanza, } \\
\text { Peru } \\
\end{array}$ & 95 & & $0 \mathrm{~km}$ & $60 \mathrm{~km}$ & $2000 \mathrm{~km}$ & $2000 \mathrm{~km}$ & $1400 \mathrm{~km}$ & $4000 \mathrm{~km}$ & $3000 \mathrm{~km}$ & $4100 \mathrm{~km}$ & $3900 \mathrm{~km}$ \\
\hline $\begin{array}{c}\text { La } \\
\text { Esperanza, } \\
\text { Peru }\end{array}$ & 95 & 0 & & $60 \mathrm{~km}$ & $2000 \mathrm{~km}$ & $2000 \mathrm{~km}$ & $1400 \mathrm{~km}$ & $4000 \mathrm{~km}$ & $3000 \mathrm{~km}$ & $4100 \mathrm{~km}$ & $3900 \mathrm{~km}$ \\
\hline $\begin{array}{c}\text { (B) La } \\
\text { Esperanza, } \\
\text { Campo Florido, } \\
\text { \& Naranjal, Peru } \\
\end{array}$ & 970 & 966 & 966 & & $2000 \mathrm{~km}$ & $2000 \mathrm{~km}$ & $1400 \mathrm{~km}$ & $4000 \mathrm{~km}$ & $3000 \mathrm{~km}$ & $4100 \mathrm{~km}$ & $3900 \mathrm{~km}$ \\
\hline Bolivia & 137 & 137 & 137 & 957 & & $0 \mathrm{~km}$ & $700 \mathrm{~km}$ & $2000 \mathrm{~km}$ & $1800 \mathrm{~km}$ & $2500 \mathrm{~km}$ & $2000 \mathrm{~km}$ \\
\hline Bolivia & 137 & 137 & 137 & 958 & 2 & & $700 \mathrm{~km}$ & $2000 \mathrm{~km}$ & $1800 \mathrm{~km}$ & $2500 \mathrm{~km}$ & $2000 \mathrm{~km}$ \\
\hline $\begin{array}{l}\text { (C) Arequipa, } \\
\text { Peru - Human }\end{array}$ & 975 & 971 & 971 & 89 & 967 & 968 & & $2700 \mathrm{~km}$ & $2500 \mathrm{~km}$ & $3200 \mathrm{~km}$ & $2500 \mathrm{~km}$ \\
\hline $\begin{array}{l}\text { São Paulo, } \\
\text { Brazil }\end{array}$ & 1044 & 1045 & 1045 & 1033 & 1045 & 1046 & 1058 & & $2100 \mathrm{~km}$ & $1300 \mathrm{~km}$ & $1100 \mathrm{~km}$ \\
\hline $\begin{array}{c}\text { Para State, } \\
\text { Brazil }\end{array}$ & 216 & 216 & 216 & 984 & 205 & 205 & 992 & 1059 & & $1500 \mathrm{~km}$ & $2800 \mathrm{~km}$ \\
\hline $\begin{array}{c}\text { Bahia State, } \\
\text { Brazil }\end{array}$ & 1284 & 1289 & 1289 & 1234 & 1287 & 1287 & 1258 & 68 & 1308 & & $2500 \mathrm{~km}$ \\
\hline $\begin{array}{c}\text { Rio Grande, } \\
\text { Brazil }\end{array}$ & 1005 & 1003 & 1003 & 82 & 1001 & 1001 & 77 & 1052 & 1026 & 1284 & \\
\hline
\end{tabular}

137 (A) 123 samples isolated from bugs, dogs, and guinea pigs in Arequipa are represented here.

138 (B) 4 samples collected in Campo Florido, Naranjal, and La Esperanza are represented here.

139 Euclidean distances (top triangle) are displayed for Santa Cruz.

140 (C) The only sample isolated from a human in Arequipa is represented here. 


\section{5}

146

147

148

149

150

151

152

153

154

155

\section{Discussion}

The invasion of recently altered environments by non-native species impacts the population health of native species as well as human health and economy. Investigation of the dynamic process of immigration and establishment of non-native species into these disturbed habitats has the potential to mitigate the impacts of pests and pathogens that are detrimental to human populations as well as agricultural and native species [17]. The analyses presented here suggest that the population of T. cruzi in Arequipa, Peru, descended from a single recent invasion. This conclusion is supported by the extremely limited genetic diversity observed among $T$. cruzi isolates sampled within and around the city, in contrast with considerable genetic diversity observed regionally and at other locales (Table 1; Fig 1). Several non-exclusive hypotheses may explain these results, including a low immigration rate, that immigration is common but immigrants rarely establish populations as a result of the low transmission rate between hosts and vectors, or that there is a high turnover rate among T. cruzi lineages.

Successful invasion of a novel geographic area is a function of the rate of immigration, the temporal duration that a habitat has been suitable for establishment, and the probability that an immigrant can reproduce and establish a population. The influx of humans and associated products and domesticated animals into Arequipa over the last $\sim 60$ years due to rapid urbanization and economic growth $[25,34]$ has provided many opportunities for $T$. cruzi immigration. However, many migrants to Arequipa come from areas in which they were not exposed to T. cruzi, such as the neighboring regions of Puno and parts of Cusco which are beyond the range of $T$. infestans [35]. Nevertheless, one $T$. cruzi lineage that does not appear to be circulating within the T. infestans population was detected in an infected human (Fig. 1),

67 suggesting that T. cruzi immigration through human movement can occur. These data suggest 
168 that multiple T. cruzi lineages may have immigrated to Arequipa with all but one failing to

169 transmit sufficiently to establish a population. While the data presented here are consistent with

170 the hypothesis that T. cruzi in Arequipa originated in Bolivia [36,37], future studies will be

171 necessary to identify the source, rate, and potential mechanism of T. cruzi immigration,

172 independent of establishment probability, through analyses of the genomic diversity in human

173 infections.

174 Prior studies across multiple species suggest that the majority of immigrants in most species

175 that reach a novel geographic area fail to establish a population due to both inhospitable local

176 environmental conditions [1,38] and stochasticity [39,40]. Environmental factors that can reduce

177 establishment probabilities include unfavorable abiotic conditions, limited food resources or

178 vectors, or an abundance of predators or competitors. The establishment probability of immigrant

$179 T$. cruzi in an urban environment is likely depressed by a low transmission rate from infected

180 humans to vectors [41-44]. For example, many human immigrants moved to locations in the city

181 without established $T$. infestans populations [25,35], which may have resulted in few

182 opportunities for T. cruzi transmission from infected immigrant humans to insect vectors, thus

183 curtailing establishment probabilities. Further, the transmission probability of T. cruzi from $T$.

184 infestans that do acquire the parasite to novel hosts is low $[42,45,46]$, thus reducing the

185 probability that a recently-immigrated T. cruzi lineage will establish a population. Both a low

186 probability of establishing a population due to limited contact between $T$. infestans and infected

187 immigrant humans or due to the limited probability of transmission from vectors to host are

188 consistent with the observation of only a single established T. cruzi lineage in vectors in

189 Arequipa. 
The observed establishment probability is likely independent of competition among T. cruzi

191 lineages. Competitive exclusion - where an existing population prevents the invasion of new

192 immigrants - appears unlikely as the majority of city blocks do not contain T. cruzi [25,47]

193 despite substantial vector populations [48]. Under the competitive exclusion hypothesis, one

194 might expect different T. cruzi lineages establishing in different areas of the city. Indeed,

195 multiple $T$. cruzi lineages do co-circulate within the same locality [44,49-53], as seen in the

196 samples sequenced here from La Esperanza (Fig 1), and even within the same host [54,55],

197 suggesting that competition is not preventing the establishment of multiple lineages in Arequipa.

198 The limited genetic diversity within Arequipa could result from a recent replacement of a

199 previously dominant lineage through natural population processes. While the continuous

200 substitution of a dominant strain through natural selection or drift is common in well-mixed

201 populations, geographic structure within populations tends to result in the persistence of genetic

202 diversity [56]. The absence of samples deriving from a previously established T. cruzi lineage in

203 the fragmented urban and inter-district landscapes, much of which contains an active vector

204 population but no $T$. cruzi $[25,47,48]$, is suggestive that no previous lineages dominated this area.

205 Additionally, no other T. cruzi lineage circulating in the vector population was detected despite

206 the temporal range of samples in our dataset (7 years).

207 In conclusion, all relevant data suggest that the vast majority of, if not all, $T$. cruzi circulating

208 in vector populations prior to the recently-controlled epidemic in the city of Arequipa descended

209 from a single immigrant. The single divergent lineage found in a human patient suggests that $T$.

210 cruzi may regularly immigrate to the city but that immigrants rarely establish populations. Low

211 genetic diversity, coupled with minimal gene flow into the city, could limit the phenotypic

212 diversity that results in variable effectiveness of treatment options and diagnoses regularly 
213 associated with Chagas disease [57,58]. However, a potential downside of the limited diversity is

214 that many currently available diagnostics may be ineffective against the local lineage [59,60], as

215 seen in Arequipa [61]. It may be necessary to use locally-optimized diagnostics in endemic

216 regions, which highlights the difficulties in diagnosing T. cruzi infection in immigrants to non-

217 endemic countries such as the United States [62,63].

218 Methods

219 Ethics Statement

220 The Institutional Animal Care and Use Committee (IACUC) of Universidad Peruana Cayetano

221 Heredia reviewed and approved the animal-handling protocol used for this study (identification

222 number 59605). The IACUC of Universidad Peruana Cayetano Heredia is registered in the

223 National Institutes of Health at the United States of America with PHS Approved Animal

224 Welfare Assurance Number A5146-01 and adheres to the Animal Welfare Act of 1990 [64].

225 Sample collection

226 DNA from 133 T. cruzi isolates collected over 7 years (2008 to 2015) were analyzed to

227 determine phylogenetic relationships (Fig 2; Fig 3; Fig S1). The majority of samples were

228 isolated from $T$. infestans bugs collected from houses throughout Arequipa $(\mathrm{N}=114)$. Three of

229 these samples were obtained using xenodiagnosis as described in Chiari \& Galvão (1997). An

230 additional ten samples from Arequipa were isolated from the blood of guinea pigs $(\mathrm{N}=7)$, dogs

$231(\mathrm{~N}=2)$, and a human $(\mathrm{N}=1)$. Six isolates were derived from Panstrongylus lignarius $(\mathrm{N}=5)-$ also

232 known as $P$. herreri [65] - and one guinea pig $(\mathrm{N}=1)$ collected in the small towns of La

233 Esperanza, Campo Florido, and Naranjal in northern Peru [33]. Cultures of three previously

234 established strains isolated from humans in Bolivia (Bol-SH001 and Bol-DH29) and São Paulo, 
235 Brazil (TC-y) were provided by the Infectious Diseases Research Laboratory at Universidad

236 Peruana Cayetano Heredia (Fig 3).

237 T. cruzi was isolated from vertebrates $(\mathrm{N}=8)$ using an adaptation of an artificial feeding

238 system that was originally described in Harington (1960) [66]. Briefly, each blood sample was

239 collected with citrate-phosphate-dextrose, transferred into a small plastic jar, and covered with a

240 latex membrane fitted tightly with a rubber band. The jars were placed into an incubator and

241 gradually heated to $35^{\circ} \mathrm{C}$. Once the temperature was reached, the jars were inverted to allow

242 uninfected T. infestans to feed through the membrane for 15 minutes. T. cruzi from the eight

243 laboratory-infected T. infestans, all 114 naturally-infected T. infestans, and five naturally-

244 infected P. lignarius were passaged through guinea pigs or mice in order to avoid isolating other

245 microbes present in the vector, as described in Castillo-Neyra et al. (2016) [67]. Feces from

246 infected vectors were injected into guinea pigs or mice and T. cruzi was isolated from the blood

247 of each experimentally-infected mammal. T. cruzi were directly isolated in LIT culture media

248 from the blood samples of three naturally-infected guinea pigs collected in Arequipa without

249 passage through $T$. infestans.

250 Reference sequences of three T. cruzi isolates obtained from NCBI database were used in

251 subsequent analyses: Silvio, isolated from a human in Para State, Brazil; Esmeraldo, isolated

252 from a human in Bahia State, Brazil; and CL Brener, isolated from a human in Rio Grande,

253 Brazil [68] (Fig 3).

254 Sequencing

255 DNA from all laboratory cultures was extracted using Qiagen DNEasy DNA Purification Kit.

256 150bp single-end read libraries were prepared using TruSeq Nano kit and sequenced to an

257 average depth of $>50 X$ using Illumina's NextSeq500. Six T. cruzi isolates were prepared in 
258 duplicate, and one in triplicate, to allow estimation of sequencing error. Low quality bases were

259 trimmed from raw reads using trimmomatic-0.32 [69].

260 Sequence assembly

261 Bowtie2 [70] was used to assemble maxicircle sequences to the most closely related

262 reference sequence, Silvio (gi|225217165|gb|FJ203996.1), obtained from NCBI [68]. Duplicate

263 reads were removed from the assembly using Picard's MarkDuplicates functionality [71]. The

264 assembly had an average depth of $>600 \mathrm{X}$ across all maxicircles. Maxicircle consensus sequences

265 were determined using VarScan [72], ensuring highly-confident base calls by requiring a $60 \%$

266 match to call each SNP.

267 Maxicircle alignment

268 All assembled maxicircle sequences and the reference were aligned to the Silvio partial 269 maxicircle sequence (gi|225217165|gb|FJ203996.1|), Esmeraldo strain complete maxicircle

$270 \quad$ (gi|85718082|gb|DQ343646.1), and the CL Brener complete maxicircle

271 (gi|85718081|gb|DQ343645.1) downloaded from the NCBI database. The sequences were

272 aligned using MUSCLE as implemented in MEGA7 [73]. The ends were trimmed so that all

273 sequences started and ended on the same nucleotide, resulting in a final alignment of $15357 \mathrm{bp}$.

274 Phylogenetic analyses

275 Phylogenetic analyses of the $15357 \mathrm{bp}$ maxicircle sequence from all samples and reference

276 strains were performed using BEAST 1.8.4 [74]. Phylogenetic analyses assumed a model of

277 sequence evolution in which the rates of $A \rightarrow T, C \rightarrow G$, and $G \rightarrow T$ are equal (123343) with $\gamma$ -

278 distributed rate heterogeneity. An Extended Bayesian Skyline tree prior [75] with constant

279 evolutionary rates across lineages (strict clock) was chosen based on BEAST Model Test

280 implemented in BEAST2 [76]. Starting with a UPGMA tree and running one Markov chain 
281 Monte-Carlo chain for each of five independent runs of 20 million iterations sampling every

2822000 iterations ensured sufficient mixing after a $10 \%$ burn-in (ESS values $>200$ in Tracer v1.6.0)

283 [77]. Tree files were combined using LogCombiner1.8.4, excluding a 10\% burn-in for each. A

284 Maximum Clade Credibility tree was generated from the combined tree file using TreeAnnotator

285 1.8.4 and FigTree v1.4.2 was used to visualize tree files (available at http://beast.bio.ed.ac.uk).

286 Phylogenetic analyses were performed using the BEAGLE library to increase computation speed

$287 \quad[78,79]$.

288 Statistical Analyses

289 Metrics of population genetic variation, $\pi$ and $\theta$, were calculated using MEGA7 [73].

290 Assuming the sample from 123 infected T. infestans is representative of the T. cruzi population

291 in vectors in Arequipa, the probability that a distinct lineage could be co-circulating but not

292 detected by chance can be calculated using a binomial distribution. The minor lineage must

293 constitute less than $2.41 \%$ of the total population in order for there to be a statistically significant

294 chance that a distinct lineage was not detected in any of 123 sampled T. cruzi.

295

296

297

298

299

300

301

302 


\section{Figures and Tables}

Figure 1. The extant T. cruzi population in Arequipa arose from a single, recent

307

308

309

310

introduction. Maximum clade credibility (MCC) tree shows that (A) all 123 T. cruzi isolated from bugs and domestic mammals in Arequipa form a monophyletic clade with a single, recent common ancestor, indicative of a single immigration event in the recent past. Despite substantial genetic diversity among T. cruzi throughout South America, those collected in Arequipa show little diversity. (B) Three samples collected in Campo Florido and Naranjal, Peru and one sample from La Esperanza, Peru have nearly identical maxicircle sequences and form a monophyletic clade. La Esperanza, Peru contains at least two distinct T. cruzi lineages, suggesting multiple independent introductions. (C) The only T. cruzi sample isolated from a human in Arequipa is distinct from all other samples from Arequipa, suggesting that this introduction has not established in the city. All tips represent a single sample except (A) $(\mathrm{N}=123)$ and (B) $(\mathrm{N}=4)$. All nodes have strong support (posterior probability $\geq 0.99$ ). Nodes are collapsed when the samples contained have nearly identical maxicircle sequences.

\section{Figure 2. Spatial distribution of samples collected in (A) Arequipa, Peru and (B) South}

America. (A) The names of ten districts from which T. cruzi samples were collected are labeled. Houses from which isolates were collected are represented by red dots. Lines represent major roadways. Densely populated areas appear grey due to the density of roads. Map of Arequipa with sample locations was generated using QGIS v. 2.1 [80]. (B) The sites where isolates were collected are represented by blue dots. Neighboring towns of La Esperanza, Campo Florido, and Naranjal are represented by a single blue dot labeled "Northern Peru". Sequences obtained from 
327 NCBI database are represented by red dots. Map of South

328 America was modified from https://commons.wikimedia.org/wiki/Atlas_of_the_world.

Figure 3. Number of samples collected from each host species per location. Most samples

$331(\mathrm{~N}=124)$ were collected in Arequipa and 6 from small towns in northern Peru. 3 isolates were

332 provided by the Infectious Diseases Research Laboratory at Universidad Peruana Cayetano

333 Heredia. Maxicircle sequences for 3 T. cruzi lineages were downloaded from the NCBI database.

Figure S1. Sample collection locations and sources. 


\section{Acknowledgements}

352

The authors would like to thank Philippe Lemey for his advice regarding the use of Bayesian

353 phylogenetics. The authors would also like to acknowledge Stephanie Seifert and Jill Devine for

354 their assistance in the laboratory. The authors gratefully acknowledge the members of

355 the Universidad Peruana Cayetano Heredia and the University of Pennsylvania Zoonotic Disease

356 Research Lab in Arequipa, Peru, for their contributions, especially Carlos Condori and Luis

357 Zamudio. The authors also thank Danitza Pamo, Jose Ylla, Jose Qusipe, Paul Picardo and

358 Gabriela Bustamante for their contribution during the isolation and maintenance of the T. cruzi

359 strains. In addition, the authors wish to acknowledge the support provided by the following

360 institutions: Ministerio de Salud del Perú (MINSA), the Dirección General de Salud de las

361 Personas (DGSP), the Estrategia Sanitaria Nacional de Prevención y Control de Enfermedades

362 Metaxenicas y Otras Transmitidas por Vectores (ESNPCEMOTVS), the Dirección General de

363 Salud Ambiental (DIGESA), the Gobierno Regional de Arequipa, the Gerencia Regional de

364 Salud de Arequipa (GRSA), the PanAmerican Health Organization (PAHO/OPS) and the

365 Canadian International Development Agency (CIDA). 


\section{Literature Cited}

375 1. McKinney ML. Urbanization, biodiversity, and conservation. BioScience. 2002;52: 883-

$376 \quad 890$.

377 2. Foley JA, DeFries R, Asner GP, Barford C, Bonan G, Carpenter SR, et al. Global 378 consequences of land use. Science. American Association for the Advancement of Science; 2005;309: 570-574.

3. Seto KC, Güneralp B, Hutyra LR. Global forecasts of urban expansion to 2030 and direct impacts on biodiversity and carbon pools. Proceedings of the National Academy of Sciences. National Acad Sciences; 2012;109: 16083-16088.

4. Theoharides KA, Dukes JS. Plant invasion across space and time: factors affecting nonindigenous species success during four stages of invasion. New Phytol. 2007;176: 256-273.

5. Kowarik I. On the role of alien species in urban flora and vegetation. Plant InvasionsGeneral Aspects and Special Problems. 1995; 85-103.

6. Hahs AK, McDonnell MJ, McCarthy MA, Vesk PA, Corlett RT, Norton BA, et al. A global synthesis of plant extinction rates in urban areas. Ecol Lett. Wiley Online Library; 2009;12: 1165-1173.

7. Aronson MF, La Sorte FA, Nilon CH, Katti M, Goddard MA, Lepczyk CA, et al. A global analysis of the impacts of urbanization on bird and plant diversity reveals key anthropogenic drivers. Proc R Soc B. The Royal Society; 2014;281: 20133330.

9. McIntyre NE. Ecology of urban arthropods: A review and a call to action. an. 2000;93:

8. Denys C, Schmidt H. Insect communities on experimental mugwort (Artemisia vulgaris

10. Deguines N, Julliard R, De Flores M, Fontaine C. Functional homogenization of flower visitor communities with urbanization. Ecology and evolution. Wiley Online Library; 2016;6: 1967-1976.

11. New TR. Promoting and developing insect conservation in Australia's urban

403 12. Mackin-Rogalska R, Pinowski J, Solon J, Wojcik Z. Changes in vegetation, avifauna, and 404 small mammals in a suburban habitat. Polish Ecological Studies. 1988;14: 293-330.

405 13. Pekin BK, Pijanowski BC. Global land use intensity and the endangerment status of 406 mammal species. Diversity and Distributions. Wiley Online Library; 2012;18: 909-918. 
14. Blair RB. Birds and butterflies along urban gradients in two ecoregions of the United States: Is urbanization creating a homogeneous fauna? Biotic Homogenization. 2001;:3356.

15. Strohbach MW, Haase D, Kabisch N. Birds and the city: urban biodiversity, land use, and socioeconomics. Ecology and Society. JSTOR; 2009;14.

16. Alirol E, Getaz L, Stoll B, Chappuis F, Loutan L. Urbanisation and infectious diseases in a globalised world. The Lancet Infectious Diseases. Elsevier; 2011;11: 131-141.

17. Crowl TA, Crist TO, Parmenter RR, Belovsky G, Lugo AE. The spread of invasive species and infectious disease as drivers of ecosystem change. Frontiers in Ecology and the Environment. Wiley-Blackwell; 2008;6: 238-246.

18. Vitousek PM, D Antonio CM, Loope LL, Westbrooks R. Biological invasions as global environmental change. American Scientist. Research Triangle Park; 1996;84: 468-478.

19. Seto KC, Fragkias M, Güneralp B, Reilly MK. A meta-analysis of global urban land expansion. PLoS ONE. Public Library of Science; 2011;6: e23777.

20. Beninde J, Veith M, Hochkirch A. Biodiversity in cities needs space: a meta-analysis of factors determining intra-urban biodiversity variation. Ecol Lett. Wiley/Blackwell (10.1111); 2015;18: 581-592.

21. Deplazes P, Hegglin D, Gloor S, Romig T. Wilderness in the city: the urbanization of Echinococcus multilocularis. Trends in Parasitology. 2004;20: 77-84.

22. Bradley CA, Altizer S. Urbanization and the ecology of wildlife diseases. Trends in Ecology \& Evolution. Elsevier; 2007;22: 95-102.

23. Harrington LC, Scott TW, Lerdthusnee K, Coleman RC, Costero A, Clark GG, et al. Dispersal of the dengue vector Aedes aegypti within and between rural communities. The American Journal of Tropical Medicine and Hygiene. 2005;72: 209-220.

24. Adalja AA, Sell TK, Bouri N, Franco C. Lessons learned during dengue outbreaks in the United States, 2001-2011. Emerg Infect Dis. 2012;18: 1-7.

25. Levy MZ, Barbu CM, Castillo Neyra R, Quispe-Machaca VR, Ancca Juárez J, EscalanteMejia P, et al. Urbanization, land tenure security and vector-borne Chagas disease. Proc Biol Sci. The Royal Society; 2014;281: 20141003-20141003.

26. Levy MZ, Bowman NM, Kawai V, Waller LA, Cornejo del Carpio JG, Benzaquen EC, et al. Periurban Trypanosoma cruzi-infected Triatoma infestans, Arequipa, Peru. Emerg Infect Dis. Centers for Disease Control and Prevention; 2006;12: 1345-1352.

27. Levy MZ, Kawai V, Bowman NM, Waller LA, Cabrera L, Pinedo-Cancino VV, et al. Targeted screening strategies to detect Trypanosoma cruzi infection in children. PLOS Neglected Tropical Diseases. Public Library of Science; 2007;1: e103. 
28. Levy MZ, Small DS, Vilhena DA, Bowman NM, Kawai V, Cornejo del Carpio JG, et al. Retracing micro-epidemics of Chagas disease using epicenter regression. PLoS Comput Biol. Public Library of Science; 2011;7: e1002146.

29. Bowman NM, Kawai V, Levy MZ, Cornejo del Carpio JG, Cabrera L, Delgado F, et al. Chagas disease transmission in periurban communities of Arequipa, Peru. CLIN INFECT DIS. 2008;46: 1822-1828.

30. Hunter GC, Borrini-Mayorí K, Ancca Juárez J, Castillo Neyra R, Verastegui MR, Malaga Chavez FS, et al. A field trial of alternative targeted screening strategies for Chagas disease in Arequipa, Peru. PLOS Neglected Tropical Diseases. Public Library of Science; 2012;6: e1468.

31. Foley EA, Khatchikian CE, Hwang J, Ancca Juárez J, Borrini-Mayorí K, Quispe-Machaca VR, et al. Population structure of the Chagas disease vector, Triatoma infestans, at the urban-rural interface. Molecular Ecology. 2013;22: 5162-5171.

32. Gaunt MW, Yeo M, Frame IA, Stothard JR, Carrasco HJ, Taylor MC, et al. Mechanism of genetic exchange in American trypanosomes. Nature. Macmillian Magazines Ltd. SN ; 2003;421: 936-939.

33. Alroy KA, Huang C, Gilman RH, Quispe-Machaca VR, Marks MA, Ancca Juárez J, et al. Prevalence and transmission of Trypanosoma cruzi in people of rural communities of the high jungle of Northern Peru. PLOS Neglected Tropical Diseases. Public Library of Science; 2015;9: e0003779.

34. Pedersen D, Tremblay J, Errázuriz C, Gamarra J. The sequelae of political violence: assessing trauma, suffering and dislocation in the Peruvian highlands. Social science \& medicine. Elsevier; 2008;67: 205-217.

35. Bayer AM, Hunter GC, Gilman RH, Cornejo del Carpio JG, Naquira C, Bern C, et al. Chagas disease, migration and community settlement patterns in Arequipa, Peru. PLOS Neglected Tropical Diseases. Public Library of Science; 2009;3: e567.

36. Dujardin J-P, Muñoz M, Chavez T, Ponce C, Moreno J, Schofield CJ. The origin of Rhodnius prolixus in Central America. Medical and Veterinary Entomology. 1998;12: 113.

37. de Arias AR, Schofield CJ. Triatoma infestans: pasado, presente y futuro del principal vector de la Enfermedad de Chagas en el Cono Sur. Reunión Intergubernamental INCOSURChagas. XIIa. Santiago, Chile; 2003.

38. Thomas CD. Translocation of species, climate change, and the end of trying to recreate past ecological communities. Trends in Ecology \& Evolution. Elsevier Ltd; 2011;26: 216221. 
39. Pitelka LF, Group PMW. Plant migration and climate change: a more realistic portrait of plant migration is essential to predicting biological responses to global warming in a world drastically altered by human activity. American Scientist. JSTOR; 1997;: 464-473.

40. Lockwood JL, Cassey P, Blackburn T. The role of propagule pressure in explaining species invasions. Trends in Ecology \& Evolution. 2005;20: 223-228.

41. Cohen JE, Cecere MC, Lauricella MA, Chuit R, Segura EL. Influence of humans and domestic animals on the household prevalence of Trypanosoma cruzi in Triatoma infestans populations in northwest Argentina. The American Journal of Tropical Medicine and Hygiene. ASTMH; 1998;58: 748-758.

42. Cohen JE, Gürtler RE. Modeling household transmission of American trypanosomiasis. Science. American Association for the Advancement of Science; 2001;293: 694-698.

43. Gürtler RE, Cecere MC, Lauricella MA, Cardinal MV, Kitron U, Cohen JE. Domestic dogs and cats as sources of Trypanosoma cruzi infection in rural northwestern Argentina. Parasitology. Cambridge University Press; 2007;134: 69-82.

44. Llewellyn MS, Miles MA, Carrasco HJ, Lewis MD, Yeo M, Vargas J, et al. Genome-scale multilocus microsatellite typing of Trypanosoma cruzi discrete typing unit I reveals phylogeographic structure and specific genotypes linked to human infection. PLOS Pathogens. Public Library of Science; 2009;5: e1000410.

45. Rabinovich JE, Wisnivesky-Colli C, Solarz ND. Probability of transmission of Chagas disease by Triatoma infestans (Hemiptera: Reduviidae) in an endemic area of Santiago del Estero, Argentina. Bulletin of the World Health Organization. World Health Organization; 1990;68: 737.

46. Nouvellet P, Dumonteil E, Gourbière S. The improbable transmission of Trypanosoma cruzi to human: the missing link in the dynamics and control of Chagas disease. PLOS Neglected Tropical Diseases. Public Library of Science; 2013;7: e2505.

47. Levy MZ, Tustin A, Castillo Neyra R, Mabud TS, Levy K, Barbu CM, et al. Bottlenecks in domestic animal populations can facilitate the emergence of Trypanosoma cruzi, the aetiological agent of Chagas disease. Proc R Soc B. The Royal Society; 2015;282: 20142807.

48. Billig E. Detecting and controlling insect vectors in urban environments: novel Bayesian methods for complex spatial data. Publicly Accessible Penn Dissertations. 2017. Available: https://repository.upenn.edu/edissertations/2193

49. Oliveira RP, Broude NE, Macedo AM, Cantor CR, Smith CL, Pena SDJ. Probing the genetic population structure of Trypanosoma cruzi with polymorphic microsatellites. Proceedings of the National Academy of Sciences of the United States of America. The National Academy of Sciences; 1998;95: 3776-3780. 
50. Higo H, Miura S, Horio M, Mimori T, Hamano S, Agatsuma T, et al. Genotypic variation among lineages of Trypanosoma cruzi and its geographic aspects. Parasitology International. 2004;53: 337-344.

51. Llewellyn MS, Lewis MD, Acosta N, Yeo M, Carrasco HJ, Segovia M, et al. Trypanosoma cruzi IIc: phylogenetic and phylogeographic insights from sequence and microsatellite analysis and potential impact on emergent Chagas disease. PLOS Neglected Tropical Diseases. Public Library of Science; 2009;3: e510.

52. Curtis-Robles R, Snowden KF, Dominguez B, Dinges L, Rodgers S, Mays G, et al. Epidemiology and molecular typing of Trypanosoma cruzi in naturally-infected hound dogs and associated triatomine vectors in Texas, USA. PLOS Neglected Tropical Diseases. 2017;11: e0005298-18.

53. Hodo CL, Wilkerson GK, Birkner EC, Gray SB, Hamer SA. Trypanosoma cruzi transmission among captive nonhuman primates, wildlife, and vectors. EcoHealth. Springer; 2018;: 1-11.

54. Perez CJ, Lymbery AJ, Thompson RCA. Chagas disease: the challenge of polyparasitism? Trends in Parasitology. Elsevier Ltd; 2014;30: 176-182.

55. Dumonteil E, Ramirez-Sierra M-J, Pérez-Carrillo S, Teh-Poot C, Herrera C, Gourbiére S, et al. Detailed ecological associations of triatomines revealed by metabarcoding and nextgeneration sequencing: implications for triatomine behavior and Trypanosoma cruzi transmission cycles. Scientific Reports. Springer US; 2018;8: 1-13.

56. Kerr B, Riley MA, Feldman MW, Bohannan BJ. Local dispersal promotes biodiversity in a real-life game of rock-paper-scissors. Nature Publishing Group. Nature Publishing Group; 2002;418: 171.

57. Revollo S, Oury B, Laurent J-P, Barnabé C, Quesney V, Carrière V, et al. Trypanosoma cruzi: impact of clonal evolution of the parasite on its biological and medical properties. Experimental Parasitology. Elsevier; 1998;89: 30-39.

58. Veloso VM, Carneiro CM, Toledo M, Lana M, Chiari E, Tafuri WL, et al. Variation in susceptibility to benznidazole in isolates derived from Trypanosoma cruzi parental strains. Memorias do Instituto Oswaldo Cruz. SciELO Brasil; 2001;96: 1005-1011.

59. Longhi SA, Brandariz SB, Lafon SO, Niborski LL, Luquetti AO, Schijman AG, et al. Evaluation of in-house ELISA using Trypanosoma cruzi lysate and recombinant antigens for diagnosis of Chagas disease and discrimination of its clinical forms. The American Journal of Tropical Medicine and Hygiene. ASTMH; 2012;87: 267-271.

60. Abras A, Gállego M, Llovet T, Tebar S, Herrero M, Berenguer P, et al. Serological diagnosis of chronic Chagas disease: is it time for a change? J Clin Microbiol. American Society for Microbiology; 2016;54: 1566-1572. 
61. Verani JR, Seitz A, Gilman RH, LaFuente C, Galdos-Cardenas G, Kawai V, et al. Geographic variation in the sensitivity of recombinant antigen-based rapid tests for chronic Trypanosoma cruzi infection. The American Journal of Tropical Medicine and Hygiene. 2009;80: 410-415.

62. Bern C, Montgomery SP. An estimate of the burden of Chagas disease in the United States. CLIN INFECT DIS. The University of Chicago Press; 2009;49: e52-e54.

63. Leiby DA, Nguyen ML, Proctor MC, Townsend RL, Stramer SL. Frequency of Trypanosoma cruzi parasitemia among infected blood donors with a potential association between parasite lineage and transfusion transmission. Transfusion. Wiley Online Library; 2017;57: 1426-1432.

64. Castillo Neyra R, Barbu CM, Salazar R, Borrini K, Naquira C, Levy MZ. Host-seeking behavior and dispersal of Triatoma infestans, a vector of Chagas disease, under semi-field conditions. PLOS Neglected Tropical Diseases. Public Library of Science; 2015;9: e3433.

65. Cáceres AG, Troyes L, Gonzáles-Pérez A, Llontop E, Bonilla C, Heredia N, et al. Enfermedad de Chagas en la región nororiental del Perú. I. Triatominos (Hemiptera, Reduviidae) presentes en Cajamarca y Amazonas. Revista Peruana de Medicina Experimental y Salud Publica. Instituto Nacional de Salud; 2002;19: 17-23.

66. Harington JS. A simple apparatus for the artificial feeding of Rhodnius prolixus (Hemiptera, Reduviidae). Parasitology. Cambridge University Press; 1960;50: 273-277.

67. Castillo Neyra R, Borrini-Mayorí K, Salazar Sánchez R, Ancca Suarez J, Xie S, Náquira Velarde $\mathrm{C}$, et al. Heterogeneous infectiousness in guinea pigs experimentally infected with Trypanosoma cruzi. Parasitology International. 2016;65: 50-54.

68. Geer LY, Marchler-Bauer A, Geer RC, Han L, He J, He S, et al. The NCBI BioSystems database. Nucleic Acids Research. Oxford University Press; 2010;38: D492-D496.

69. Bolger AM, Lohse M, Usadel B. Trimmomatic: a flexible trimmer for Illumina sequence data. Bioinformatics. Oxford University Press; 2014;30: 2114-2120.

70. Langmead B, Salzberg SL. Fast gapped-read alignment with Bowtie 2. Nat Methods. 2012;9: 357-359.

71. McKenna A, Hanna M, Banks E, Sivachenko A, Cibulskis K, Kernytsky A, et al. The Genome Analysis Toolkit: A MapReduce framework for analyzing next-generation DNA sequencing data. Genome Research. 2010;20: 1297-1303.

72. Koboldt DC, Chen K, Wylie T, Larson DE, McLellan MD, Mardis ER, et al. VarScan: variant detection in massively parallel sequencing of individual and pooled samples. Bioinformatics. Oxford University Press; 2009;25: 2283-2285.

73. Kumar S, Stecher G, Tamura K. MEGA7: Molecular Evolutionary Genetics Analysis Version 7.0 for Bigger Datasets. Molecular Biology and Evolution. 2016;33: 1870-1874. 
74. Drummond AJ, Suchard MA, Xie D, Rambaut A. Bayesian phylogenetics with BEAUti and the BEAST 1.7. Molecular Biology and Evolution. Oxford University Press; 2012;29: 1969-1973.

75. Heled J, Drummond AJ. Bayesian inference of population size history from multiple loci. BMC Evol Biol. 2008;8: 289-15.

590 76. Bouckaert R, Heled J, Kühnert D, Vaughan T, Wu C-H, Xie D, et al. BEAST 2: A software platform for Bayesian evolutionary analysis. PLoS Comput Biol. Public Library of Science; 2014;10: e1003537.

593 77. Rambaut A, Drummond AJ, Xie D, Baele G, Suchard MA, Susko E. Posterior

594 summarization in Bayesian phylogenetics using Tracer 1.7. Systematic Biology. 2018;22

595 78. Suchard MA, Rambaut A. Many-core algorithms for statistical phylogenetics.

596 Bioinformatics. Oxford University Press; 2009;25: 1370-1376.

597 79. Ayres DL, Darling A, Zwickl DJ, Beerli P, Holder MT, Lewis PO, et al. BEAGLE: An application programming interface and high-performance computing library for statistical phylogenetics. Systematic Biology. Oxford University Press; 2012;61: 170-173. 


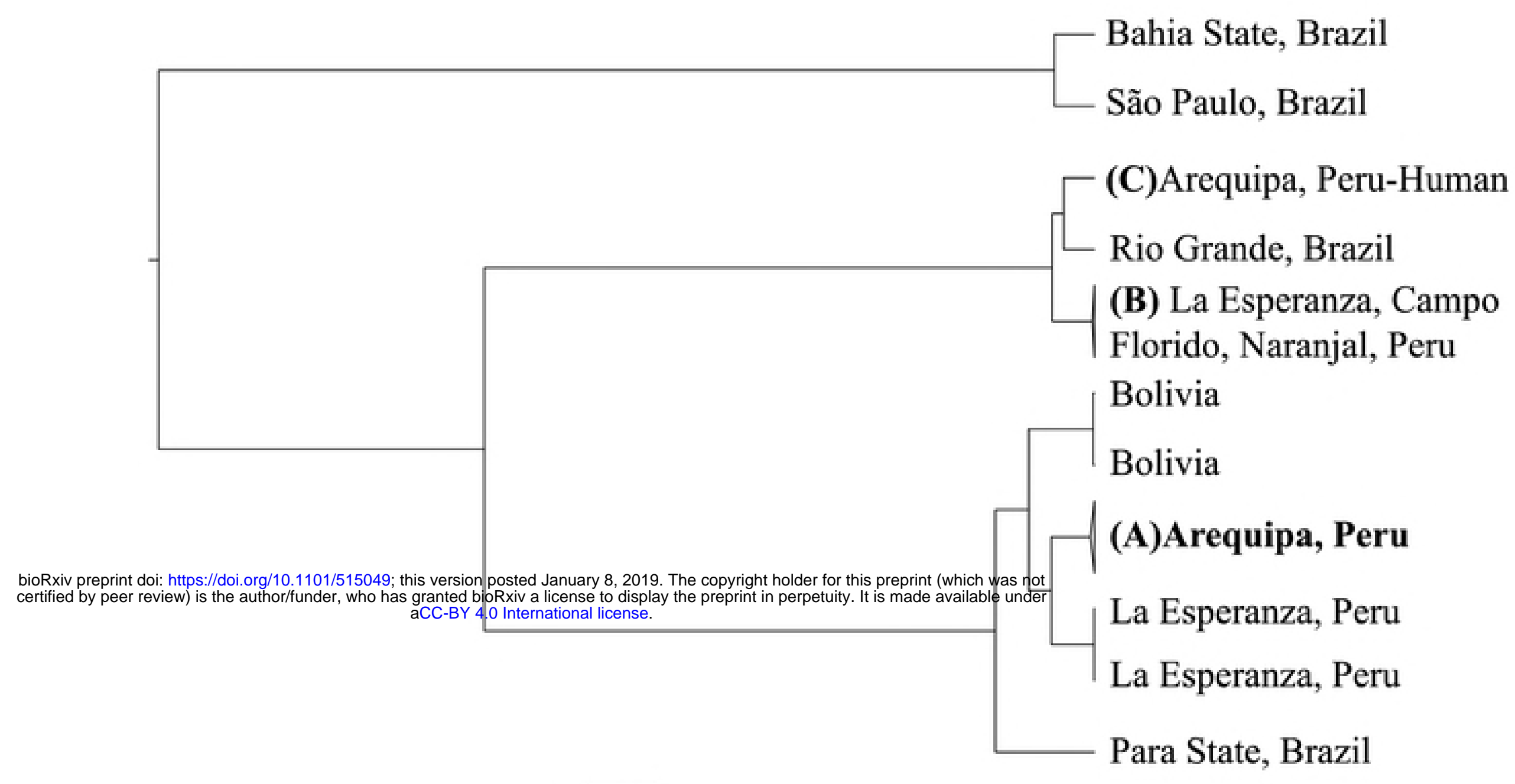

$10 \overline{\mathrm{SN}} \mathrm{Ps}$

Figure 1. The extant T. cruzi population in Arequipa arose from a single, recent introduction. Maximum clade credibility (MCC) tree shows that (A) all $123 \mathrm{~T}$. cruzi isolated from bugs and domestic mammals in Arequipa form a monophyletic clade with a single, recent common ancestor, indicative of a single immigration event in the recent past. Despite substantial genetic diversity among T. cruzi throughout South America, those collected in Arequipa show little diversity. (B) Three samples collected in Campo Florido and Naranjal, Peru and one sample from La Esperanza, Peru have nearly identical maxicircle sequences and form a monophyletic clade. La Esperanza, Peru contains at least two distinct $T$. cruzi lineages, suggesting multiple independent introductions. (C) The only T. cruzi sample isolated from a human in Arequipa is distinct from all other samples from Arequipa, suggesting that this introduction has not established in the city. All tips represent a single sample except (A) $(N=123)$ and (B) $(N=4)$. All 


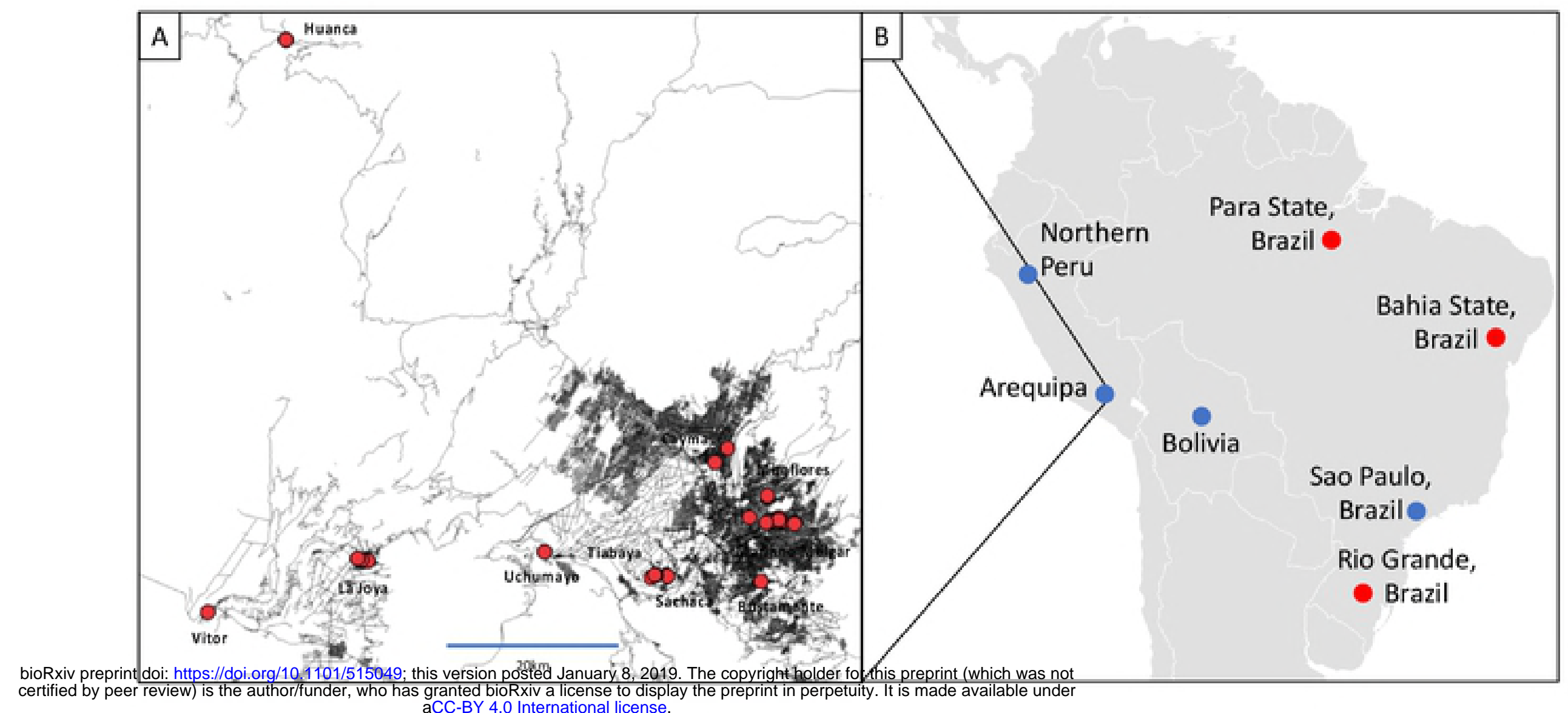

Figure 2. Spatial distribution of samples collected in (A) Arequipa, Peru and (B) South

America. (A) The names of ten districts from which T. cruzi samples were collected are labeled. Houses from which isolates were collected are represented by red dots. Lines represent major roadways. Densely populated areas appear grey due to the density of roads. Map of Arequipa with sample locations was generated using QGIS v. 2.1 [80]. (B) The sites where isolates were collected are represented by blue dots. Neighboring towns of La Esperanza, Campo Florido, and Naranjal are represented by a single blue dot labeled "Northern Peru". Sequences obtained from NCBI database are represented by red dots. Map of South America was modified from https://commons.wikimedia.org/wiki/Atlas_of_the_world. 


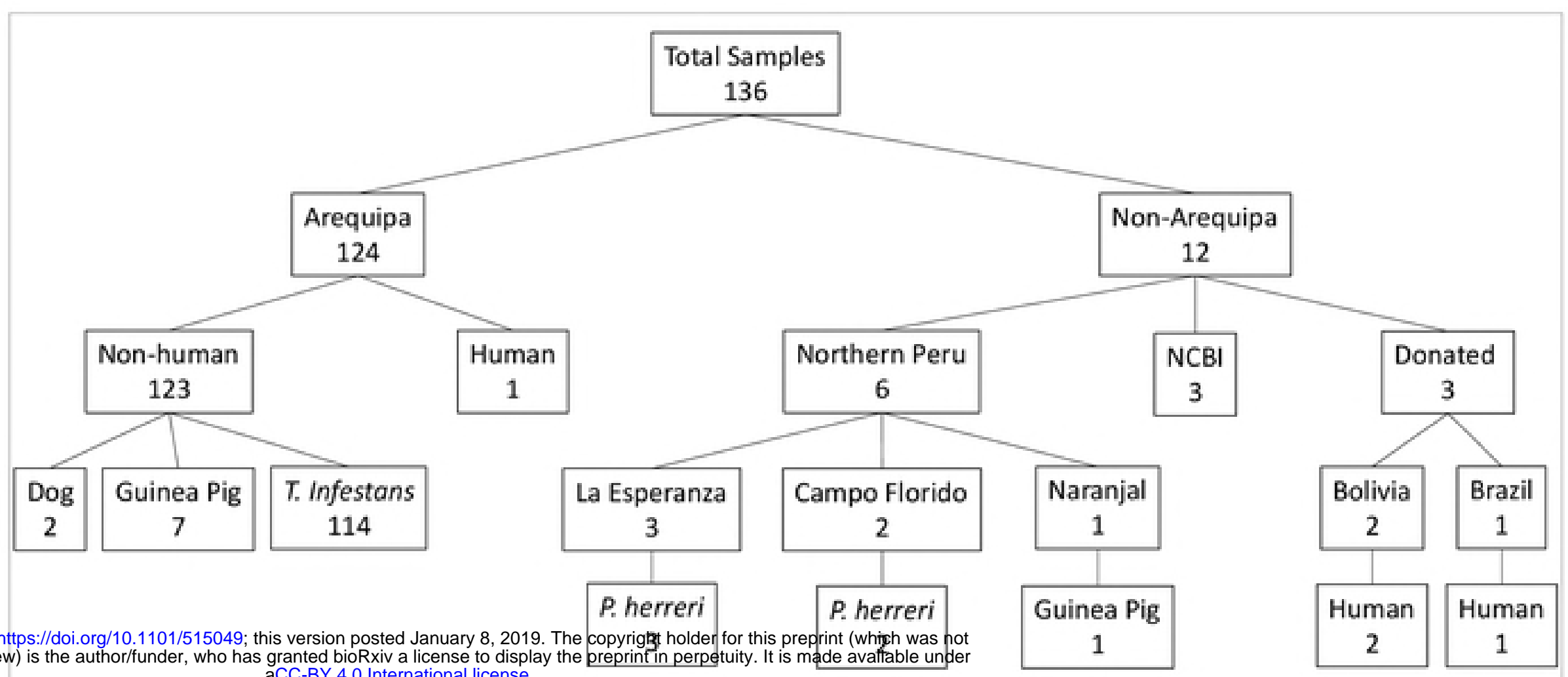

Figure 3. Number of samples collected from each host species per location. Most samples $(\mathrm{N}=124)$ were collected in Arequipa and 6 from small towns in northern Peru. 3 isolates were provided by the Infectious Diseases Research Laboratory at Universidad Peruana Cayetano Heredia. Maxicircle sequences for 3 T. cruzi lineages were downloaded from the NCBI database. 
Table S1. Sample collection source and location.

\begin{tabular}{|c|c|c|c|c|}
\hline Sample ID & Region & District & \begin{tabular}{|c|} 
Collection \\
Year
\end{tabular} & Source \\
\hline TC001 & Arequipa & La Joya & 2008 & T. infestans \\
\hline TC002 & Arequipa & La Joya & 2008 & T. infestans \\
\hline TC003 & Arequipa & La Joya & 2008 & T. infestans \\
\hline TC004 & Arequipa & La Joya & 2008 & T. infestans \\
\hline TC010 & Arequipa & Mariano Melgar & 2008 & T. infestans \\
\hline TC014 & Arequipa & La Joya & 2008 & T. infestans \\
\hline TC015 & Arequipa & La Joya & 2008 & T. infestans \\
\hline TC016 & Arequipa & La Joya & 2008 & T. infestans \\
\hline TC019 & Arequipa & La Joya & 2008 & T. infestans \\
\hline TC020 & Arequipa & La Joya & 2008 & T. infestans \\
\hline 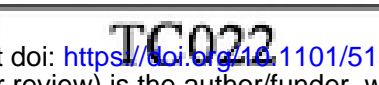 & 49; Antrequpligatat Ja & uary 8, 2019. Theacopoldayy alolder for this & eprint (mäish Wo not & T. infestans \\
\hline TC023 & 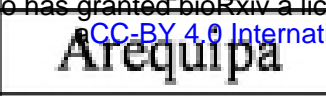 & La Joya & 2008 & Guinea pig \\
\hline TC026 & Arequipa & La Joya & 2008 & T. infestans \\
\hline TC027 & Arequipa & La Joya & 2008 & T. infestans \\
\hline TC029 & Arequipa & La Joya & 2008 & T. infestans \\
\hline TC031 & Arequipa & La Joya & 2008 & T. infestans \\
\hline TC033 & Arequipa & La Joya & 2008 & T. infestans \\
\hline $\mathrm{TC} 034$ & Arequipa & La Joya & 2008 & T. infestans \\
\hline TC035 & Arequipa & La Joya & 2008 & T. infestans \\
\hline TC036 & Arequipa & La Joya & 2008 & T. infestans \\
\hline TC037 & Arequipa & La Joya & 2008 & T. infestans \\
\hline TC038 & Arequipa & La Joya & 2008 & T. infestans \\
\hline TC039 & Arequipa & La Joya & 2008 & T. infestans \\
\hline TC040 & Arequipa & La Joya & 2008 & T. infestans \\
\hline TC041 & Arequipa & Mariano Melgar & 2010 & Dog \\
\hline $\mathrm{TC} 042$ & Arequipa & Mariano Melgar & 2010 & Guinea pig \\
\hline TC043 & Arequipa & Mariano Melgar & 2010 & Guinea pig \\
\hline TC044 & Arequipa & Mariano Melgar & 2010 & Dog \\
\hline TC045 & Arequipa & Mariano Melgar & 2010 & Guinea pig \\
\hline TC046 & Arequipa & Mariano Melgar & 2010 & T. infestans \\
\hline TC047 & Arequipa & Mariano Melgar & 2010 & T. infestans \\
\hline TC048 & Arequipa & Mariano Melgar & 2010 & T. infestans \\
\hline TC049 & Arequipa & Mariano Melgar & 2010 & T. infestans \\
\hline TC050 & Arequipa & J.L.B. y Rivero & 2009 & Human \\
\hline TC051 & Arequipa & Miraflores & 2010 & T. infestans \\
\hline TC052 & Cajamarca & La Esperanza & 2010 & P. herreri \\
\hline
\end{tabular}

